\title{
Pesquisa de anticorpos contra Leptospira spp. em animais silvestres e em estado feral da região de Nhecolândia, Mato Grosso do Sul, Brasil. Utilização da técnica de imuno- histoquímica para detecção do agente*
}

\author{
Investigation of antibodies to Leptospira spp. in wild and feral animals from the region of Nhecolândia, Mato \\ Grosso do Sul, Brazil. Use of the immunohistochemistry technique for the agent detection
}

\section{Raul José Silva Girio ${ }^{1}$ Fernando Lúcio Garcia Pereira ${ }^{2}$ Moacir Marchiori Filho ${ }^{3}$ Luís Antônio Mathias $^{1}$ Rita de Cássia Pereira Herreira ${ }^{4}$ Antônio Carlos Alessi ${ }^{1}$ Thaís Marino Silva Girio ${ }^{5}$}

RESUMO

Foram examinadas 315 amostras de soros sangüíneos de diversas espécies de animais que vivem em estado feral ou silvestre na região de Nhecolândia, Corumbá, MS, por meio da prova de soroaglutinação microscópica para leptospirose. Dessas amostras, 67 foram de bois baguás (Bos taurus indicus), 39 de porcos-monteiros (Sus scrofa), 39 de búfalos (Bubalus bubalis), nove de quatis (Nasua nasua), 41 de veados-campeiros (Ozotoceros bezoarticus), 10 de veados-mateiros (Mazama americana) e 110 amostras de ovinos (Ovis aries). Em 12 animais que vieram a óbito, seis porcos-monteiros, quatro veados-campeiros e dois ovinos, foram realizadas tentativas de isolamento de leptospira do fígado e dos rins por cultura em meio semi-sólido. Fragmentos desses órgãos foram submetidos a exame histopatológico e também a exame para deteç̧ão das leptospiras pela técnica de imuno-histoquímica. Os resultados dos exames sorológicos mostraram que $64(20,3 \%)$ das amostras foram reagentes para pelo menos um sorovar de leptospira patogênica; foram reagentes $41,0 \%$ das amostras de búfalos, $40,3 \%$ das de bois baguás, 17,9\% das de porcos-monteiros, $9 \%$ das de ovinos e 9,7\% das amostras de veados-campeiros; nenhuma das amostras de veados-mateiros e de quatis foi reagente. Os sorovares mais freqüentes foram: pomona, para búfalos $e$ ovinos; icterohaemorrhagiae, para ovinos, veados-campeiros e suínos; e copenhageni, para veados-campeiros e suínos. As tentativas de isolamento dos rins e fígados foram todas negativas, e pela técnica da imuno-histoquímica foi detectada leptospira no fígado de um porco-monteiro. As principais alterações estruturais, encontradas nos rins de dois veadoscampeiros e de um porco-monteiro, foram infiltrados inflamatórios intersticial com congestão associada a hemorragias.
Palavras-chave: leptospirose, animais silvestres, sorologia, imuno-histoquímica.

\section{ABSTRACT}

Three hundred and fifteen serum samples of several animal species living in wild or in feral state in the area of Nhecolândia, Corumbá, MS, Brazil, were examined by the microscopic agglutination test. Of these samples, 67 were of feral bovine (Bos taurus indicus), 39 of feral pigs (Sus scrofa), 39 of buffaloes (Bubalus bubalis), nine of coatis (Nasua nasua), 41 of pampas deer (Ozotoceros bezoarticus), 10 of brocket deer (Mazama americana) and 110 of feral sheep (Ovis aries). In 12 dead animals (six feral pigs, four pampas deer and two feral sheep), isolation attempts and leptospira identification through the immunohistochemistry were accomplished. Sixty-four (20.3\%) of the samples reacted to at least one serovar of pathogenic leptospira; $41.0 \%$ of the buffaloes, $40.3 \%$ of the feral bovine, $17.9 \%$ of the feral pigs, 9\% of the feral sheep, and $9.7 \%$ of the pampas deer serum samples were reactors. All the serum samples of brocket deer and of coatis were not reactors. The most frequent serovars for the studied animal species were: pomona for buffaloes and feral sheep; icterohaemorrhagiae for feral sheep, pampas deer and feral pigs; and copenhageni for pampas deer and feral pigs. The attempts of leptospira isolation resulted negative, and the immunohistochemistry analysis revealed leptospira in the liver of one feral pig. Microscopic examination of the kidney revealed vascular congestion, hemorrhage and infiltration of mononuclear inflammatory cells in the interstice.

Key words: leptospirosis, wild animals, feral animals, serology, immunohistochemistry.

\footnotetext{
${ }^{*}$ Auxílio financeiro - Fapesp

${ }^{2}$ Faculdade de Ciências Agrárias e Veterinárias Campus de Jaboticabal - Unesp, 14884-900

${ }^{3}$ Curso de Graduação em Medicina Veterinária - FCAVJ/Unesp - Iniciação Científica - Fapesp

${ }^{4}$ Médico Veterinário - Vallée S.A.

${ }^{5}$ Médica Veterinária - Defesa Agropecuária do Mato Grosso do Sul

${ }^{6}$ Curso de Graduação em Medicina Veterinária - Centro Universitário Barão de Mauá - Ribeirão Preto
} 


\section{INTRODUÇÃO}

A leptospirose acomete, praticamente, todos os animais domésticos, silvestres e o homem, provocando ou não a manifestação de sintomas. Animais de muitas espécies domésticas, bem como a maioria das espécies silvestres, podem tornar-se portadores e contribuírem para a disseminação do microrganismo na natureza. A eliminação da leptospira pela urina dos portadores ocorre por períodos de tempo que podem variar de poucas semanas a vários meses, entre os animais domésticos, e por toda vida no caso dos roedores (WEBSTER et al., 1995).

WANYANGU et al. (1987) encontraram, no Quênia, 15,5\% de búfalos selvagens (Syncerus caffer) reagentes; os sorovares icterohemorrhagiae e canicola foram considerados os mais freqüentes. Em búfalos (S. caffer) da África do Sul, MYBURGH et al. (1990) encontraram 1,7\% de reagentes aos sorovares tarassovi e hardjo. CHAUDHRY et al. (1996) verificaram que $16 \%$ das amostras de soro sangüíneo de búfalos (Bubalus bubalis) da área rural do distrito de Shekhupura (Paquistão) foram reagentes contra os sorovares icterohaemorrhagiae e mini.

VASCONCELLOS et al. (1997) examinaram soros bovinos de diversos estados e verificaram que, no Estado do Mato Grosso do Sul, 70,5\% das amostras foram reagentes; o sorovar hardjo foi o predominante.

Em suínos selvagens da Austrália, PAVLOV (1991) encontrou prevalências de 2\% a 23\% de reagentes para o sorovar pomona em sete regiões estudadas no Norte de Queensland, e MASON et al. (1998) observaram que 20\% de suínos abatidos por caçadores em New South Wales apresentaram títulos sorológicos $\geq 1 / 50$ para leptospira, a grande maioria contra o sorovar pomona.

Embora alguns trabalhos de pesquisa sobre a leptospirose em animais silvestres tenham sido realizados nas Américas, no Brasil a enfermidade ainda é pouco estudada nas espécies nativas da fauna de cada região, deixando uma possível lacuna no estudo da cadeia epidemiológica, o que dificulta a elaboração de planos estratégicos de controle dessa doença em regiões com grande densidade de animais, matas e rios.

Pesquisas têm demonstrado a distribuição da leptospirose em várias espécies de cervídeos, em diferentes países. Nos Estados Unidos da América, INGEBRIGTSEN et al. (1986) verificaram que 3\% de soros de cervos-do-rabo-branco (Odocoileus virginianus) no Estado de Minnesota foram reagentes contra variantes sorológicas de leptospiras patogênicas; GOYAL et al. (1992) observaram, nessa mesma espécie e no mesmo estado americano, que $43 \%$ foram reagentes contra os sorovares bratislava e pomona. NEW et al. (1993), no Estado do Tennessee, encontraram, em cervos dessa mesma espécie, freqüências de $8 \%$ a $28 \%$ de reagentes contra os sorovares hardjo, pomona e icterohaemorrhagiae.

No Brasil, MATHIAS et al. (1999) realizaram um levantamento sorológico para leptospirose em veados-campeiros (Ozotoceros bezoarticus) do Pantanal Mato-grossense, MS, e do Parque Nacional de Emas, GO; 24\% das amostras do Pantanal Matogrossense foram reagentes, contra os sorovares hardjo, wolffi ou mini, e nenhuma amostra do Parque Nacional de Emas foi reagente.

Considerando a escassez de dados no Brasil, o presente trabalho teve como objetivo pesquisar a ocorrência de títulos de anticorpos contra variantes sorológicas de leptospiras em animais domésticos que vivem em estado feral e em algumas espécies de animais silvestres brasileiras como quati (Nasua nasua), veadocampeiro (Ozotoceros bezoarticus) e veado-mateiro (Mazama americana) capturados no Pantanal Matogrossense.

\section{MATERIALEMÉTODOS}

\section{Amostras}

Foram colhidas 315 amostras de sangue dos seguintes animais: 67 amostras de boi baguá (Bos taurus indicus), 39 amostras de porco-monteiro (Sus scrofa), 39 amostras de búfalos (Bubalus bubalis), nove amostras de quati (Nasua nasua), 41 amostras de veado-campeiro (Ozotoceros bezoarticus), 10 amostras de veado-mateiro (Mazama americana) e 110 amostras de ovinos (Ovis aries). Todos esses animais foram capturados pelos técnicos do Departamento de Inspeção e Defesa Agropecuária do Mato Grosso do Sul na região de Nhecolândia, município de Corumbá, no Estado do Mato Grosso do Sul. Dos 315 animais capturados, 12 morreram por motivos variados, como estresse, fraturas e traumatismos cranianos. Desses animais, foram retirados rins e fígados para pesquisar a presença de leptospiras. Foram obtidos órgãos dos seguintes animais: seis porcos-monteiros, quatro veadoscampeiros e dois ovinos.

\section{Pesquisa de anticorpos no soro sangüíneo}

Os soros sangüíneos foram testados pela prova de soroaglutinação microscópica (SAM), realizada segundo as recomendações de SANTA ROSA (1970), contra 24 sorovares de Leptospira: australis, bratislava, autumnalis, butembo, castellonis, canicola, whitcombi, cynopteri, 
grippotyphosa, hebdomadis, copenhageni, icterohaemorrhagiae, javanica, panama, pomona, pyrogenes, hardjo, wolffi, shermani, mini, andamana, patoc, buenos aires e sentot.

Os sorovares de leptospira foram repicados semanalmente, em meio líquido EMJH (Difco), tendo como inóculo $10 \%$ do volume do meio. Foram utilizados apenas cultivos puros, isentos de contaminação, livres de auto-aglutinação, com cinco a sete dias de crescimento e, por estimativa de densidade, contendo cerca de 100 a 200 leptospiras por campo microscópico.

As amostras de soros foram diluídas em solução tamponada de Sorënsen, inicialmente na diluição 1/100, para triagem. Foi considerado reagente o soro com $50 \%$ de aglutinação. As amostras reagentes na triagem foram reexaminadas até sete diluições seriadas de razão dois. O título do soro foi considerado a recíproca da sua maior diluição a apresentar 50\% de aglutinação.

A leitura das reações foi realizada em microscópio de campo escuro após a incubação da mistura soro-antígeno por três horas em temperatura de $28^{\circ} \mathrm{C}$.

\section{Tentativa de isolamento de leptospira}

Fragmentos dos rins dos 12 animais mortos foram triturados e macerados, separadamente, em solução salina tamponada de Sörensen esterilizada, na concentração de $10 \%$ do volume. Em seguida foram preparadas duas diluições seriadas de razão dez, de tal modo a serem obtidas as concentrações finais de $10 \%$, $1 \%$ e $0,1 \%$. Cada uma dessas concentrações foi semeada em tubo de Fletcher normal e em outro acrescido de 5fluorouracil (Hoffman-Roche) na concentração final de $100 \mu \mathrm{g} / \mathrm{mL}$. O volume de inóculo por tubo de meio foi de 0,1 mL (FAINE, 1982).

\section{Técnica anatomopatológica}

Os fragmentos de fígado e rins foram fixados em suspensão de formalina tamponada a $10 \%$, incluídos em blocos de parafina, cortados a $7 \mu \mathrm{m}$ de espessura e a seguir foram corados pela técnica de $\mathrm{HE}$, segundo BEHMER et al. (1976).

\section{Reação de imuno-histoquímica}

Os fragmentos dos rins dos animais que morreram durante a captura foram fixados em solução de formalina tamponada a $10 \%$ e incluídos em blocos de parafina, cortados em micrótomos, deixados em estufa a $30^{\circ} \mathrm{C}$ para distensão do corte e submetidos à reação de imuno-histoquímica com anti-soros para o sorovar pomona (POLAK \& VAN NOORDEN, 1986), para a pesquisa de antígenos de leptospira. A leitura das lâminas foi realizada em microscópio óptico com condensador de campo escuro.

\section{RESULTADOSE DISCUSSÃO}

Os resultados obtidos pela técnica de SAM, realizada em todas as amostras examinadas, estão expressos na tabela 1. Do total de 315 amostras das diversas espécies estudadas, 64 (20,3\%) foram reagentes contra pelo menos um sorovar de leptospira patogênica, e 251 (79,7\%) não foram reagentes. A maioria das amostras reagentes apresentou títulos de anticorpos entre 100 e 800 ; somente uma amostra de ovino apresentou título de 3.200.

Entre os soros de búfalos (Bubalus bubalis) em estado feral e selvagens a prevalência foi de $41,0 \%$ de reagentes contra cinco diferentes variantes sorológicas de leptospiras. Esses dados foram diferentes daqueles verificados por WANYANGU et al. (1987) em búfalos de origem africana e de CHAUDHRY et al. (1996) em búfalos asiáticos vivendo em zona rural e urbana. O fato do Bubalus bubalis apresentar uma preferência por áreas úmidas pode facilitar a disseminação do agente etiológico, principalmente em regiões como o Pantanal.

Do total de 67 amostras de boi baguá (Bos taurus indicus), 27 (40,3\%) foram reagentes, o que demonstra uma alta prevalência, que também foi

Tabela 1 - Freqüência de animais vivendo em estado feral ou silvestre e examinados pelo teste de soroaglutinação microscópica aplicada à leptospirose, segundo a espécie animal e a natureza do resultado. Nhecolândia, Mato Grosso do Sul, 1998-1999.

\begin{tabular}{|c|c|c|c|c|c|}
\hline \multirow{2}{*}{ Espécies } & \multicolumn{2}{|c|}{ Reagentes* } & \multicolumn{2}{|c|}{$\begin{array}{c}\text { Não } \\
\text { Reagentes }\end{array}$} & \multirow[t]{2}{*}{ Total } \\
\hline & № & $\%$ & $\mathrm{~N}^{0}$ & $\%$ & \\
\hline $\begin{array}{l}\text { Búfalo } \\
\text { Bubalus bubalis }\end{array}$ & 16 & 41,0 & 23 & 59,0 & 39 \\
\hline $\begin{array}{l}\text { Boi baguá } \\
\text { Bos taurus indicus }\end{array}$ & 27 & 40,3 & 40 & 59,7 & 67 \\
\hline $\begin{array}{l}\text { Porco-monteiro } \\
\text { Sus scrofa }\end{array}$ & 07 & 17,9 & 32 & 81,9 & 39 \\
\hline $\begin{array}{l}\text { Ovino } \\
\text { Ovis aries }\end{array}$ & 10 & 9,0 & 100 & 91,0 & 110 \\
\hline $\begin{array}{l}\text { Veado-campeiro } \\
\text { Ozotoceros bezoarticus }\end{array}$ & 4 & 9,7 & 37 & 90,2 & 41 \\
\hline $\begin{array}{l}\text { Veado-mateiro } \\
\text { Mazama americana }\end{array}$ & 0 & 0,0 & 10 & 100,0 & 10 \\
\hline $\begin{array}{l}\text { Quati } \\
\text { Nasua nasua }\end{array}$ & 0 & 0,0 & 9 & 100,0 & 9 \\
\hline Total & 64 & 20,3 & 251 & 79,7 & 315 \\
\hline
\end{tabular}

*Reagente $=$ título $=100$ para pelo menos um dos 24 sorovares de Leptospira sp.

Ciência Rural, v. 34, n. 1, jan-fev, 2003. 
observada por VASCONCELLOS et al. (1997) no Estado do Mato Grosso do Sul. Os resultados reforçam a importância dessa espécie na manutenção da leptospira no ambiente dessa região. Naquela pesquisa, o sorovar hardjo foi o mais freqüente, enquanto no presente trabalho o sorovar wolffi foi o de maior ocorrência. Vale ressaltar que oito amostras de boi baguá apresentaram reações cruzadas entre os sorovares wolffi e buenos aires, com títulos de 100 a 400, e em uma as reações cruzadas ocorreram entre os sorovares wolffi e andamana, título de 100. Essas reações de aglutinação heterólogas podem revelar que os animais possivelmente foram infectados naturalmente pelos sorovares patogênicos e apatogênicos, uma vez que estes podem estar presentes no ambiente.

Das 39 amostras de porco-monteiro, 17,9\% foram reagentes, de modo semelhante aos resultados de PAVLOV (1991) e MASON et al. (1998), que encontraram $23 \%$ e $20 \%$ de reagentes, respectivamente, em suínos selvagens. Os sorovares encontrados com maior freqüência nos porcos-monteiros foram icterohaemorrhagiae e copenhageni, diferindo dos outros autores, que encontraram o sorovar pomona como o mais freqüente.

Apenas 10 (9\%) das 110 amostras analisadas de ovinos (Ovis aries) vivendo em estado feral foram reagentes; os sorovares icterohaemorrhagiae e pomona foram os que apresentaram aglutinação com maior freqüência.

Nas espécies silvestres, verificou-se que quatro $(9,7 \%)$ das 41 amostras de veado-campeiro (Ozotoceros bezoarticus) examinadas eram reagentes: duas contra o sorovar wolffi, uma contra o sorovar mini e uma contra o sorovar hardjo. Esse percentual foi menor do que encontraram MATHIAS et al. (1999), nessa mesma região (24\%), contudo os sorovares encontrados foram os mesmos. Na espécie Odocoileus virginianus, cervídeo que habita os Estados Unidos da América, INGEBRIGTSEN et al. (1986), GOYAL et al. (1992) e NEW et al. (1993) encontraram os sorovares bratislava, pomona, icterohaemorrhagiae e hardjo como os mais freqüentes.

As amostras sorológicas de quati (Nasua nasua) e veado-mateiro (Mazama americana) foram todas negativas no teste de SAM. Entretanto, não se pode descartar a possibilidade dessas espécies serem reservatórios da bactéria, uma vez que o número de amostras examinadas foi pequeno.

Não se obteve sucesso nas tentativas de isolamento de leptospira dos rins.

As alterações histopatológicas encontradas nos rins dos animais que tiveram óbito foram infiltrado inflamatório intersticial com congestão associada a hemorragia, em um veado-campeiro e em um porcomonteiro.

Os resultados da reação de imunohistoquímica revelaram a presença de leptospira somente no fígado de um porco-monteiro, o mesmo animal em cujo rim foram observadas alterações histopatológicas. Não foi detectada a presença de leptospira nos rins e no fígado de amostras dos veadoscampeiros, ovinos e dos outros cinco porcos-monteiros que morreram durante a captura.

O presente trabalho revelou que várias espécies de animais silvestres ou que vivem em estado feral podem manter leptospiras no ecossistema matogrossense. Devido ao grande número de espécies que vivem na região e em se tratando de um ambiente propício à sobrevivência e disseminação das leptospiras, essas e outras espécies devem ser melhor estudadas, de forma a se obter uma melhor compreensão da cadeia epidemiológica da leptospirose no Pantanal Matogrossense.

\section{CONCLUSÕES}

Das sete espécies de animais estudadas que vivem em estado feral ou silvestre no Pantanal Matogrossense, cinco foram reagentes contra leptospiras patogênicas; os búfalos e os bois baguás foram as espécies com maiores percentuais de reagentes (41\% e $40,3 \%$ ), respectivamente, seguidos pelo porcomonteiro, com $17,9 \%$.

Os sorovares de maior freqüência, detectados por sorologia, foram pomona (búfalo e ovino), wolffi (boi baguá), icterohaemorrhagiae (ovino, veado-campeiro e suínos) e copenhageni (veado-campeiro e suínos). As amostras de veadomateiro (Mazama americana) e de quati (Nasua nasua) foram negativas para todas as variantes sorológicas de leptospiras pesquisadas.

No presente trabalho foi possível detectar, por meio da reação de imuno-histoquímica, a presença de leptospiras no tecido hepático de um porco-monteiro morto durante a captura.

\section{REFERÊNCIAS BIBLIOGRÁFICAS}

BEHMER, O.A., TOLOSA, E.M.C., FREITAS NETO, A.G. Manual de técnicas para histologia normal e patológica. São Paulo: Edart, 1976. 158 p.

CHAUDHRY, J.I., et al. Seroprevalence of leptospirosis in buffaloes. Buffalo Journal, v.12, n.1, p.65-71, 1996.

FAINE, S. Guidelines for the control of leptospirosis. Geneve: World Health Organization, 1982. 171p. 
GOYAL, S.M., MECH, L.M., NELSON, M.E. Prevalence of antibody titers to Leptospira spp in Minnesota white-tailed deer. J Wild Dis, v. 28, n. 3, p. 445-448, 1992.

INGEBRIGTSEN, D.K., LUDWING, J.R., McCLURKIN, A. W. Occurrence of antibodies to the etiologic agents of infectious bovine rhinotracheits, parainfluenza 3, leptospirosis and brucellosis in white-tailed deer in Minnesota. J Wild Dis v. 22, n. 1, p. 83-86, 1986.

MASON, R.J., et al. Leptospira interrogans antibodies in feral pigs from New South Wales. J Wild Dis, v.34, n.4, p. 738743, 1998

MATHIAS, L.A., GIRIO, R.J.S., DUARTE, J.M.B. Serosurvey for antibodies against Brucella abortus and Leptospira interrogans in pampas deer from Brazil. J Wild Dis, v.35, n.1, p. 112-114, 1999 .

MYBURGH, J.G., et al. Serological reations to Leptospira species in buffalo (Syncerus caffer) from the Kruger National Park. Onderst Aus J Vet Res, v.57, n.4 p.281282, 1990.

NEW, J.C.Jr., WATHEN, W.G., DEUTKOWSKI, S. Prevalence of Leptospira antibodies in white-tailed deer, Cades Cove, Great Smoky Mountains National Park, Tennesse, U.S.A. J Wild Dis, v.29, p.561-577, 1993.
PAVLOV, P.M. Aspects of the ecology of the feral pig (Sus scrofa) in semi-arid and tropical areas of eastern Australia. Melbourne, 1991. 325p. Thesis (PhD - Biology Science), Monash University Australia, 1991

POLAK, J.M., VAN NOORDEN, S. Immunohistochemistry: Modern methods and applications. 2 ed. Bristol: Wright, 1986. 702p.

SANTA ROSA, C.A. Diagnóstico laboratorial da leptospirose. Vet Microbiol, v.1, n.9, p.97-109, 1970

VASCONCELLOS, S.A., BARBARINI JÚNIOR, O., UMEHARA, O. et al. Leptospirose bovina. Níveis de ocorrência e sorotipos predominantes em rebanhos dos Estados de Minas Gerais, São Paulo, Rio de Janeiro, Paraná, Rio Grande do Sul e Mato Grosso do Sul. Período de Janeiro a Abril, 1996. Arq Inst Biol, v.64, n.2, p.7-15, 1997.

WANYANGU, S.W., OLUBAYO, R.O., ROSITTER, P.B. et al. The study of the ecology and prevalence of leptospirosis in large wild ruminants and domesticated bovines found in Kenya. Israel J Vet Med, v.43, n.4, p.340-341, 1987.

WEBSTER, J.P., ELLIS, W.A., MACDONALD, D.W Prevalence of Leptospira spp. in wild brown rats (Rattus norvegicus) on UK farms. Epidemiol Infect, v.114, n.1, p.195-201, 1995. 